\title{
A long-term study of threshold values and output characteristics of cardiac pacemakers ${ }^{1}$
}

\author{
GEORGE G. JÁROS, PAUL MARCHAND, \\ MORRIS MILNER, AND I. W. P. OBEL \\ From the Cardiovascular Research Unit and Departments of Thoracic Surgery and Electrical \\ Engineering, University of the Witwatersrand
}

The characteristics of electrical stimuli which activate ventricular muscle were investigated by Prevost and Battelli in 1899. Later they were more accurately evaluated by Orias, Brooks, Suckling, Gilbert, and Siebens (1950). Zoll (1952) appears to have been the first to use stimuli with a duration of 2 to $3 \mathrm{msec}$. for clinical pacing of the heart. As far as we are aware, no attempts have been made to confirm that this range of pulse durations remains optimal with the passage of time. In this paper we present the results of a prolonged investigation of threshold variations using different pulse durations. As a result of our findings we suggest that the performance of implantable pacemakers might be improved if impulses longer than 2 to $3 \mathrm{msec}$. were adopted.

\section{EXPERIMENTAL PROCEDURE}

Five patients with complete heart block controlled with external pacemakers were subjected to long-term threshold measurements. Two patients had Elema type EMT 567 electrodes sewn to the heart and three had Chardack helical coil electrodes implanted and their wires were exteriorized remotely through the skin. Voltage and current pacing thresholds were periodically measured for up to a year after electrode implantation. These thresholds were determined with a Disa, 'Multistim' pulse generator which delivers square impulses of variable amplitude ( 0 to $50 \mathrm{~mA}$ out of 1 megohm and 0 to $50 \mathrm{~V}$ out of $3 \mathrm{ohms}$ ), frequency $(0.1$ to $1,000 \mathrm{c} / \mathrm{sec}$.), and duration $(0.02$ to 1,000 msec.). Pacing was initiated with amplitudes above the expected current or voltage threshold levels, and effective ventricular contractions were confirmed by monitoring the elecrocardiogram with an oscilloscope. Thresholds were reached by slowly lowering the stimulator output until pacing stopped and then immediately increasing it until the beat was recaptured. The thresholds were determined for pulse duratións ranging from 0.7 to $30 \mathrm{msec}$. Measurements

${ }^{1}$ Requests for reprints to : P. Marchand, F.R.C.S., 6th Floor, Florence Nightingale Building, 22 Kotze Street, Hospital Hill, Johannesburg, South Africa were made daily while the patients were in hospital and thereafter weekly and later monthly.

Two dogs with surgically induced heart-block (Starzl and Gaertner, 1955) were also paced for more than three months in the same manner. Elema platinum-tipped epicardial electrodes were used, and the wires were brought out through the skin of the back.

\section{RESULTS}

The changes in pacing threshold for voltages and currents over a period of 110 days, using different pulse durations, are shown in Figures 1 and 2. As the impulse duration is shortened the current and voltage thresholds increase. The starting thresholds are not unduly different, but within three to seven days they have all risen, but at a steeper rate for short impulses than for long ones. Over four months of observations the thresholds for impulses above $10 \mathrm{msec}$. remain relatively stable at low stimulation levels. These graphs, though representing the changes in one patient only, reflect the general trend of the whole group. In Figs 3 and 4 the current and voltage thresholds with $0.7 \mathrm{msec}$ impulses are seen to be maintained at higher levels and also vary more erratically than those with $10 \mathrm{msec}$. impulses. The changes using short duration impulses occur at unpredictable times and do not stabilize within six weeks of electrode implantation, as claimed by Chardack, Gage, and Greatbatch (1960). Ten-millisecond impulse curves maintain stability virtually from the commencement of pacing. The strength-duration curves obtained in acute experiments approach their rheobase at pulse durations of 2.5 to $3 \mathrm{msec}$. (lower curve in Figs 5 and 6). However, after a period of established pacing the strength-duration curves change and not only reflect an increased amplitude but also an altered slope, so that the rheobase is then reached with stimuli of 6 to $10 \mathrm{msec}$. duration (upper curves 


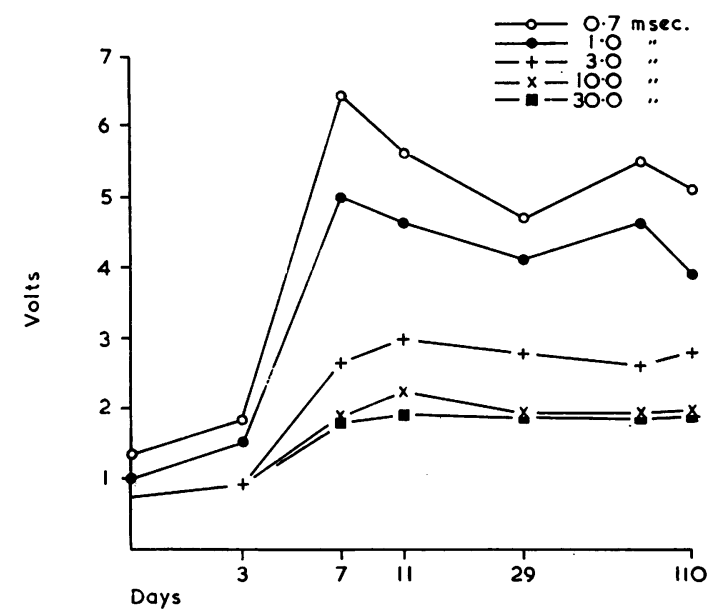

FIG. 1. Voltage threshold curves for $0.7,1,3,10$, and 30 msec. pulse durations, showing the variation of cardiac threshold voltages with the passage of time.

in Figs 5 and 6). With short impulses the threshold currents and voltages are high after seven days, whereas the passage of time has comparatively little effect on the thresholds of impulses longer than $6 \mathrm{msec}$. Even mild infection at the electrodes aggravates this tendency (Figs 7 and 8).

The influence of various impulse durations on the charge and energy supplied by the batteries was determined from the current and voltage threshold measurements illustrated in Figures 1 and 2. The charge delivered at the electrodes

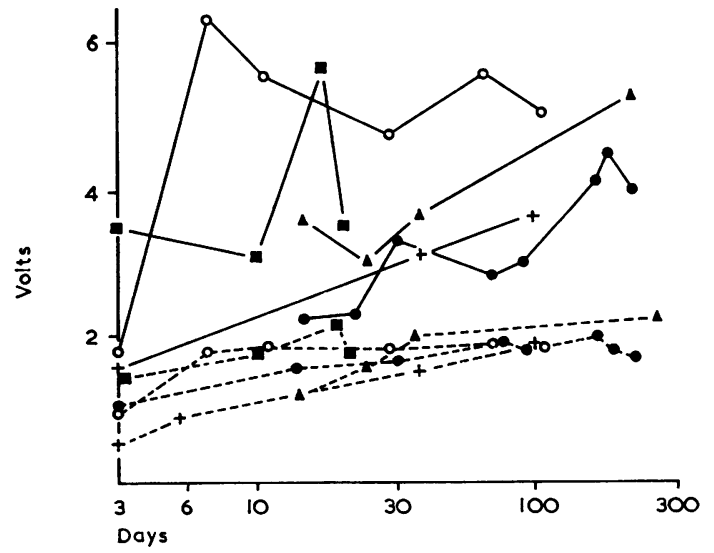

FIG. 3. Voltage thresholds measured in the five patients using $0.7 \mathrm{msec}$. (continuous line) and $10 \mathrm{msec}$. (dotted line) pulse durations plotted against the passage of time.

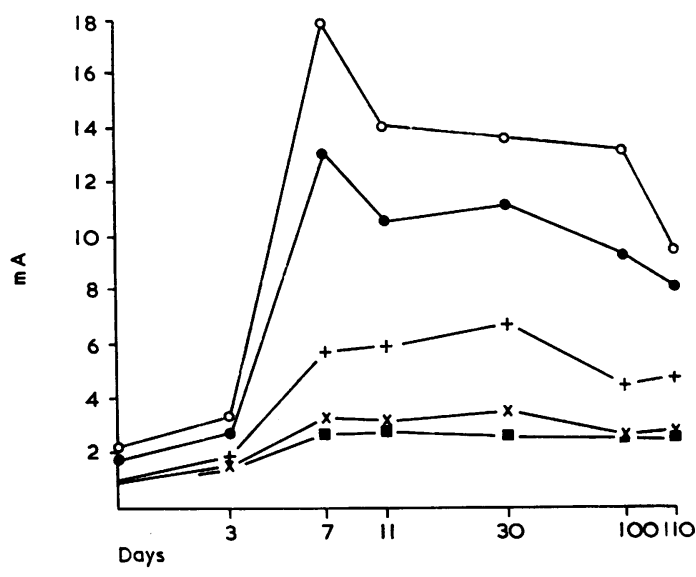

FIG. 2. Current threshold curves for $0.7,1,3,10$, and 30 msec. pulse durations, showing the variction of cardiac threshold currents with the passage of time.

changes slowly with pulse durations of up to about $6 \mathrm{msec}$., but thereafter it increases relatively rapidly (Fig. 9). The energy used to pace the heart over the 110 days of observations was not $\frac{0}{\mathbb{D}}$ markedly different for pulse durations from 1 to $10 \mathrm{msec}$. (Figs 10 and 11).

CALCULATIONS OF BATTERY REQUIREMENTS USING VARIOUS IMPULSE DURATIONS The life and bulk of the pacemaker are largely dependent upon the number and size of the batteries required. An

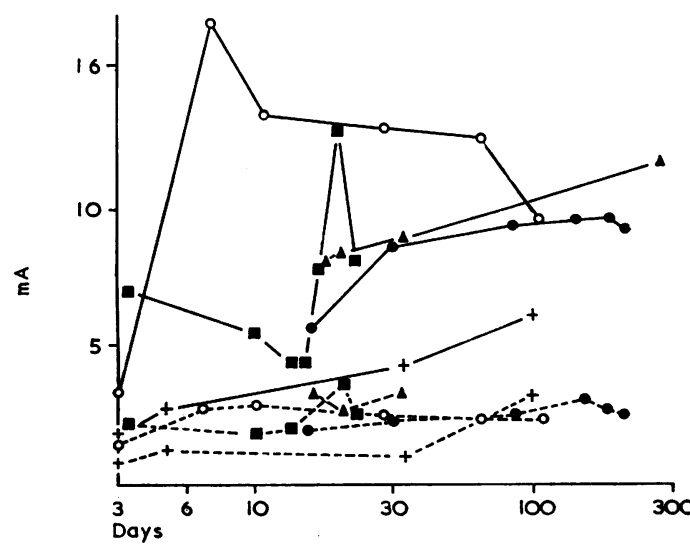

FIG. 4. Current thresholds measured in the five patients using 0.7 msec. (continuous line) and $10 \mathrm{msec}$. (dotted line) pulse durations plotted against the passage of time. 


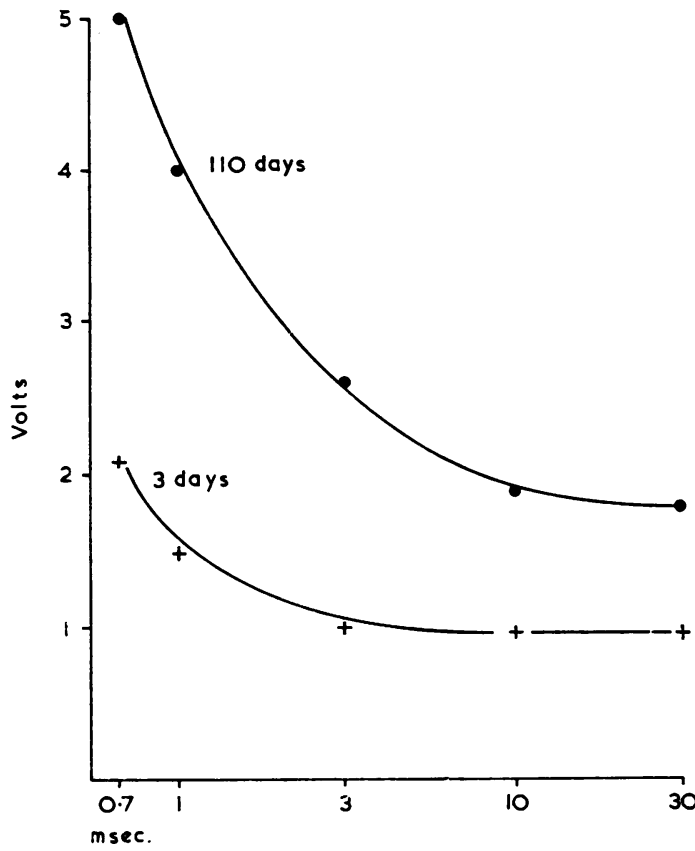

FIG. 5

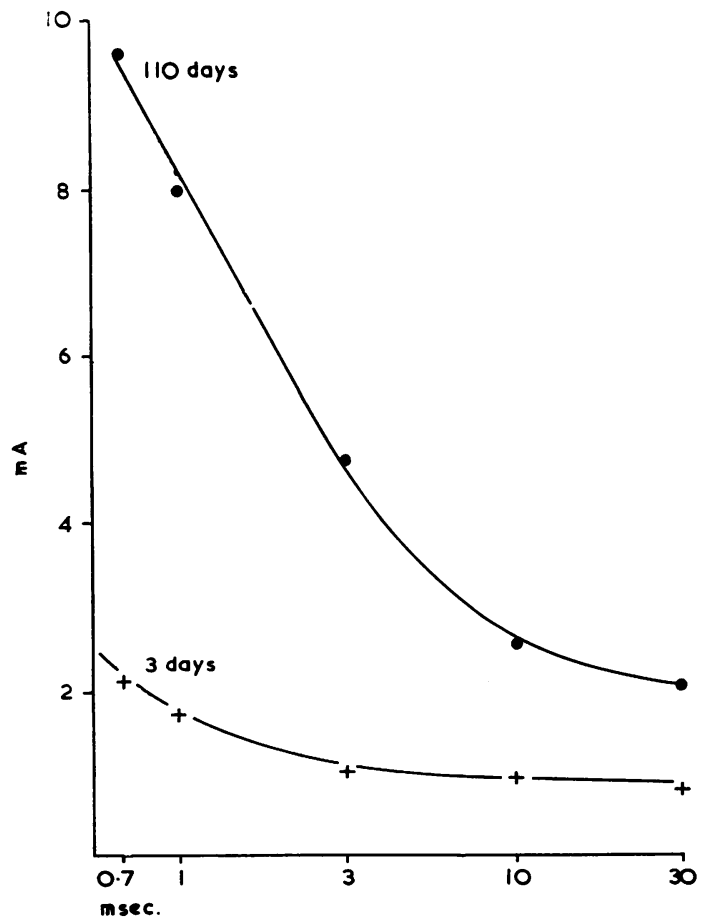

FIG. 6
FIG. 5. Voltage thresholds of a patient measured 3. and 110 days after implantation of the electrodes plotted against varying pulse durations.

FIG. 6. Current thresholds of a patient measured 3 and 110 days after implantation of the electrodes plotted against varying pulse durations.

FIG. 7. The very high values for voltage thresholds as measured in two patients with electrode sepsis; voltage is plotted against varying pulse durations $(M r . E$. at 18 months; Mrs. S. at 12 months).

FIG. 8. The increased current thresholds as measured in two patients with electrode sepsis; current is plotted against varying pulse durations (Mr. E. at 18 months; Mrs. S. at 12 months).

FIG. 9. Charge $(\mu \mathrm{C})$ delivered to the heart, plotted against pulse duration. Calculated from Fig. 2 at 7 days after implantation.

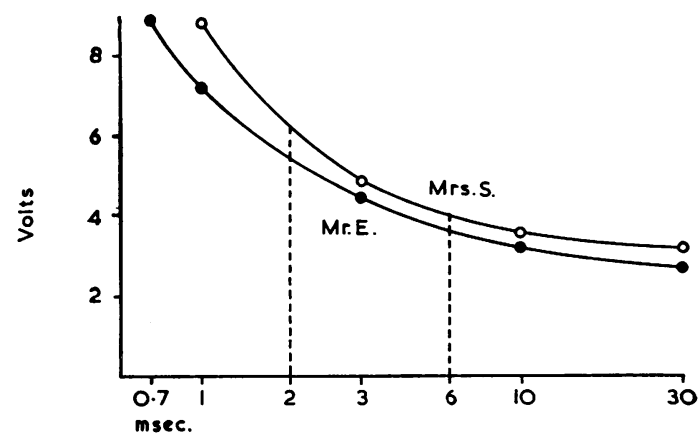

FIG. 7

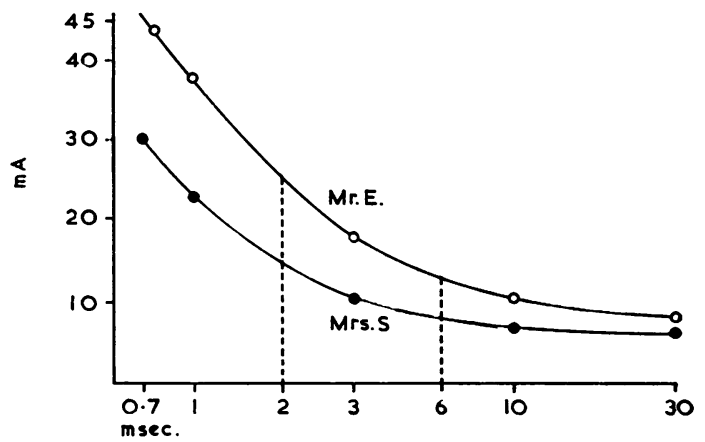

FIG. 8

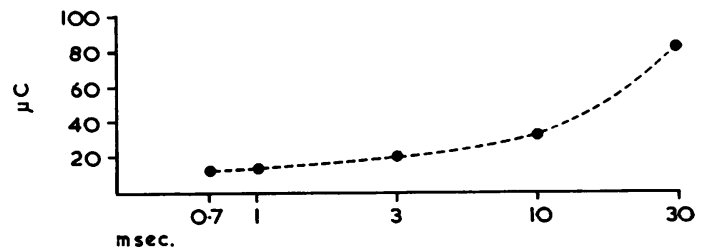

FIG. 9 


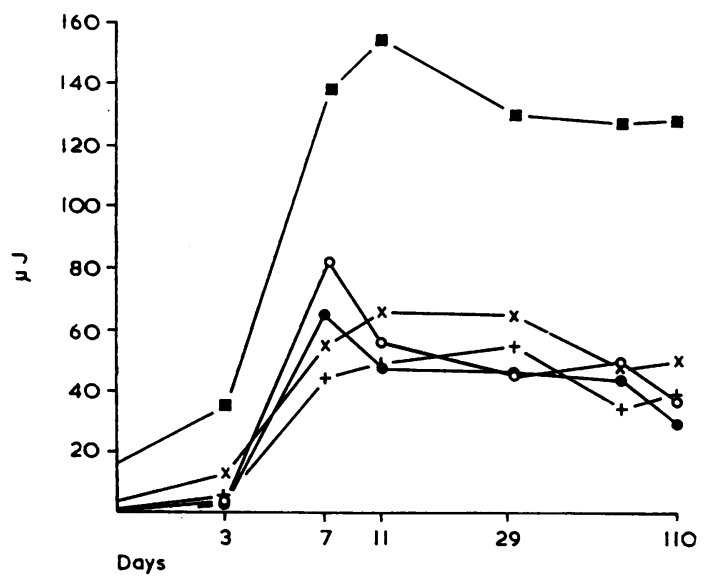

FiG. 10. Energy $(\mu J)$ for pulse durations of $0.7(O)$, $1(\bullet), 3(+), 10(x)$, and $30(\square)$ msec. used to pace the heart plotted against the passage of time (calculated from Figs 1 and 2).

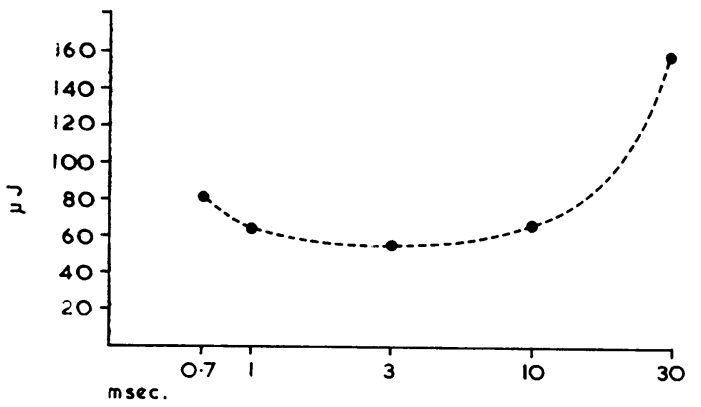

FIG. 11. Energy $(\mu J)$ needed to pace the heart plotted against pulse duration. The maximum points of each curve in Fig. 10 were used for the calculation. exact assessment of these requirements can be calculated from the curves obtained at seven days? in the case presented in Figures 5 and 6. This $\frac{}{\bar{c}}$ calculation for different pulse durations is tabu- $\frac{\vec{\Phi}}{\Phi}$ lated step by step in the Table. The voltage and 0 current thresholds are shown in rows 1 and 3 \% respectively, and in rows 2 and 4 a $50 \%$ safety $\overrightarrow{0}$ margin has been added to these respective values. From these threshold currents and pulse dura- $\vec{\omega}$ tions, and assuming a stimulation frequency of 75 pulses per minute, the current drain for the stimu- $\vec{x}$ lation can be calculated in milliampere-hours per N day (row 5). In order to produce the requiredvoltages a minimum number of cells in series. must be used (row 6). As each cell has an E.M.F.음 of $1.3 \mathrm{~V}$ the available voltage can be calculated(row 7). Knowing the current drain per day, the

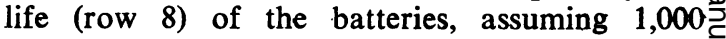
milliampere-hours capacity, can be obtained. ํㅡㄴ When pulse durations over $4.5 \mathrm{msec}$. are used it is possible to reduce the number of cells in series $\vec{\theta}$ because of the decreased voltage demands. It is. therefore possible to retain the original size and weight of the pacemaker (rows 9 and 10) by using fewer cells, but of greater capacity, connected in $\bar{\partial}$ series.

Rows 11 and 12 follow from a consideration of $\frac{\mathbb{Q}}{\varrho}$ the capacities and types of commercially avail- $\overrightarrow{\vec{D}}$ able batteries respectively. Dividing the capacity 3 figures in row 11 by the daily current drain in row 5 leads to the expected battery life shown in row 13 and plotted against pulse durations in Figure 12. Using pulse durations up to $2 \mathrm{msec}$., five cells are required. Four cells are needed when the $\stackrel{0}{x}$ stimulus duration lies between 2 and $4.5 \mathrm{msec}$, $\frac{\sigma}{3}$ but with longer stimuli three cells will suffice. (providing for a $50 \%$ safety margin in each case).

T A B LE

CALCULATIONS (BASED ON THE THRESHOLD VALUES ILLUSTRATED IN FIGS 5 AND 6) TO DETERMINE PACEMAKER LIFE AND SIZE OF BATTERIES

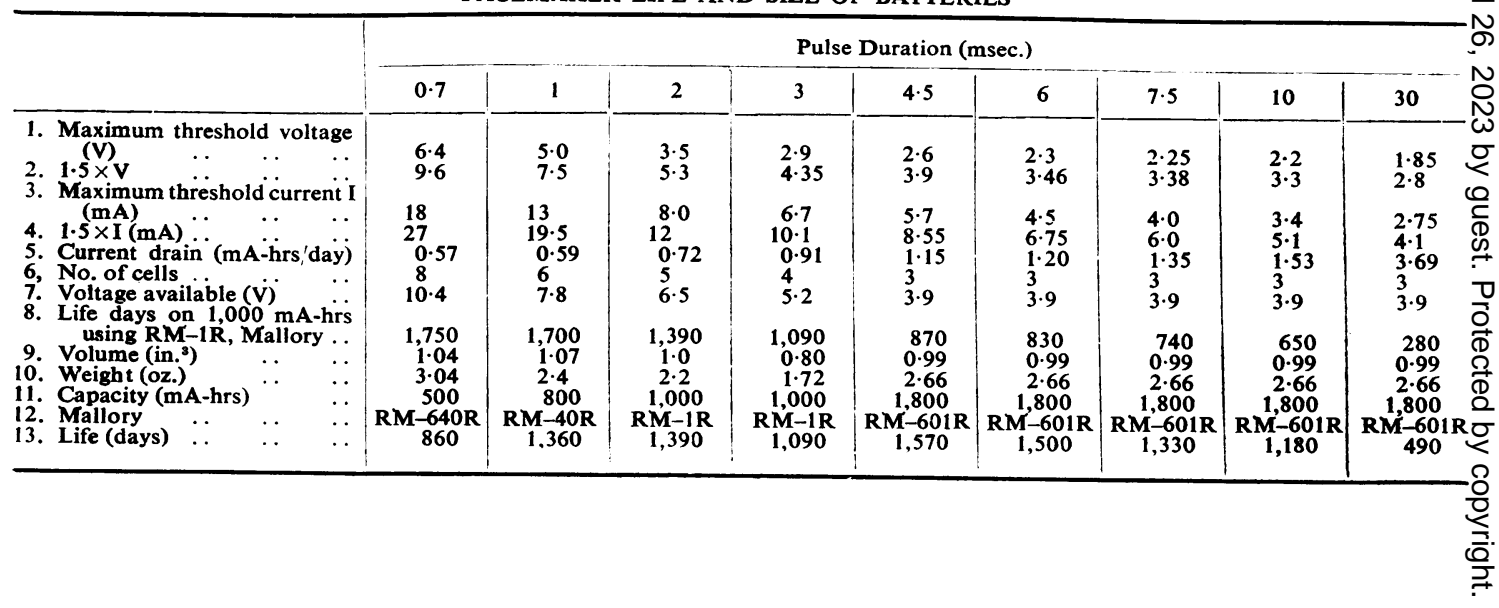




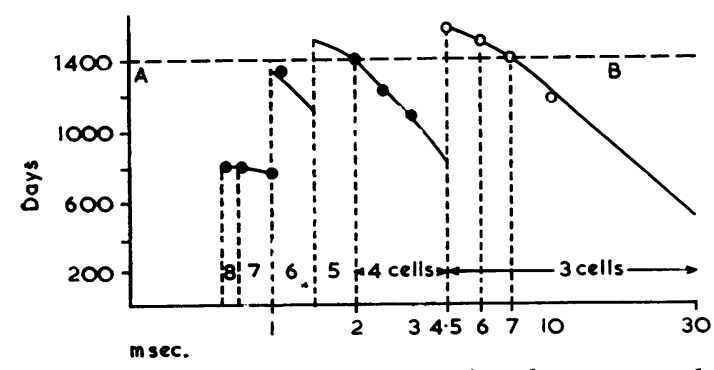

FIG. 12. Expected battery life plotted against pulse duration (discontinuities correspond to changes in the number of cells in series).

With a 2 msec. pulse duration unit a life of 1,390 days (3.81 years) can be expected from the four cells. With $6 \mathrm{msec}$. impulses using three cells a life of 1,500 days is possible.

\section{DISCUSSION}

In this discussion we deliberately avoid using the word 'resistance' when referring to threshold measurements, because the equivalent circuit of the heart is not purely resistive but has a capacitive component as well. Also the term impedance' is incorrect, because a pulse type stimulus is used, and we therefore confine our descriptions to voltage and current thresholds without attributing a term to their ratio.

Threshold stability, by which is meant the relative constancy of the voltage and current thresholds for ventricular excitation with the passage of time, is essential for continued efficacy of implantable pacemakers. Brockman, Webb, and Bahnson (1958) and Furman and Robinson (1959), using 2 to $3 \mathrm{msec}$. impulses, found that threshold levels remained constant in short-term animal studies, whilst Chardack, Gage, and Greatbatch (1961) claim that, in the absence of sepsis, thresholds stabilize within five to six weeks. The adjustable control of the Chardack-Greatbatch model 5870 was designed so that currents could be kept slightly above the individual thresholds for two reasons: firstly, so as not to exceed the margin of safety for ventricular fibrillation, and, secondly, to conserve battery life. In our experience of these units it has been necessary to increase the output (apart from the routine adjustments at six weeks) in nine out of 24 cases, in some instances as long as a year after implantation of the pacemaker. This must indicate continuing rising thresholds in a proportion of the cases. Similarly, late threshold rise has resulted in an appreciable incidence of failed pacing where fixed output units such as the St. George's and Elema were used (Marchand, Jaros, and Obel, 1967). These experiences indicate that with impulse durations of up to $3 \mathrm{msec}$., threshold stability is not uniformly attained within a relatively short period of electrode implantation. Direct measurement has confirmed that, even in the absence of sepsis, thresholds may continue to rise for several months after electrode implantation.

Lengthening of the stimulus time enhances the threshold stability. The average threshold increase at the end of 300 days in five patients tested with 0.7 msec. stimuli was $100 \%$, whereas in the same five patients tested with $10 \mathrm{msec}$. stimuli the average increase was $18 \%$ (Fig. 3). In addition, the average starting voltage threshold with $10 \mathrm{msec}$. impulses was $1.3 \mathrm{~V}$, compared with $2.5 \mathrm{~V}$ for $0.7 \mathrm{msec}$. impulses, and after 300 days the mean thresholds were $1.6 \mathrm{~V}$ and $4.8 \mathrm{~V}$ respectively. There is a close similarity between our chronic threshold findings and those of a case recorded by Weale, Deuchar, and Nightingale (1960). They implanted electrodes and measured the thresholds in an area of apparently normal myocardium and also in an obvious myocardial infarct. They found after five days that the rheobasic time with the infarct electrode was 10 to $30 \mathrm{msec}$., compared with $3 \mathrm{msec}$. for the electrode implanted into excitable muscle. Zoll and Linenthal (1963) have previously suggested that the absence of active myocardium at the electrode site causes the rising energy requirements. Scarring, infection, and myocardial necrosis all increase the distance between the electrode and the excitable myocardium. The current density emerging from an implanted electrode will vary inversely with the radial distance from the electrode. It will be highest in the immediate vicinity of the electrode and will fall inversoly with distance from it. If a Chardack electrode is regarded as a cylinder of $0.5 \mathrm{~mm}$. radius and $2 \mathrm{~mm}$. length, then at $1 \mathrm{~mm}$. from its surface the current density will be halved. Irrespective of the resistivity of surrounding scar, current continuity is maintained. The only influence of an increase in resistivity is to increase the drop in potential across the scar, which, in relation to the total applied voltage, is insignificant. The reduction in the current density in the nearest active myofibrils following the formation of scar is thus the prime factor responsible for thresho!d increase. Since the pulse duration also affects threshold stability, it appears that the capacitive component of the equivalent electrical circuit at shorter pulse durations causes a 
proportionately lesser charge to be delivered to the heart muscle than at longer pulse durations.

Zoll, Paul, Linenthal, Norman, and Gibson (1956) believed that the longer the impulse the greater was the danger of precipitating ventricular fibrillation. Brockman et al. (1958) and Nightingale and Weale (1960) favoured the clinical use of 2 to $3 \mathrm{msec}$. impulses because acute experimental strength-duration curves approached their rheobase with these pulse durations. Albert, Glass, Pittman, and Robichaux (1964) studied long-term thresholds using progressively longer pulse durations. Though they found that the voltage and current thresholds decreased to reach minimum stable values at 3 to $6 \mathrm{msec}$., they were primarily concerned with considerations of energy requirements which were lowest with pulse durations of 1.5 to $2.5 \mathrm{msec}$. For this reason they approved of the short duration pulses used in commercial pacemakers.

Stability, energy, and current drain (or charge) are the three main factors which influence the electrical behaviour of the pacemaker. Kantrowitz (1964) has shown that the ratio of voltages to current required for pacing does not change appreciably with time but that the energy requirements do increase. Our investigations show clearly that stimuli in the vicinity of $7 \mathrm{msec}$. duration provide greater long-term stability whilst the energy required for pacing remains substantially constant for the range of 1 to $10 \mathrm{msec}$. pulses. Though the current drain rises progressively with longer stimuli, it only begins to be significant for stimulus durations above $7 \mathrm{msec}$.

The problem of late rising thresholds could be overcome by designing implantable pacemakers which produce greater output currents and voltages. However, if the same life span as that of present units is to be maintained, more batteries of larger capacity resulting in an unwieldy increase in pacemaker size would be required. We have shown by calculation (see Table) that it would be possible to construct a pacemaker with $6 \mathrm{msec}$. impulses using three-cell batteries which would have a life of 1.500 days. Although even greater threshold stability is possible by further increasing the pulse duration, the battery life would then be shortened. The best compromise value of pulse duration would therefore appear to lie in the region of 6 to $7 \mathrm{msec}$. The internal drain of the circuitry which amounts to about $10 \%$ of the external drain is common to any pacemaker and can therefore be disregarded.

Our patients and experimental animals were paced with $2 \mathrm{msec}$. pulses, and this was only varied during observations. We have now paced $\stackrel{\vec{\rho}}{?}$ three patients with external units using $6 \mathrm{msec}$. pacing stimuli and two dogs with induced heart-음 block using embedded pacemakers with the same $\frac{\bar{s}}{\partial}$ pulse duration for periods of up to nine months. $\stackrel{\mathbb{Q}}{\Omega}$ The three patients are alive and have suffered no episodes of arrhythmia or other ill effects which $\overrightarrow{0}$ could be attributed to the length of stimulus used. $\stackrel{\circ}{-}$ One of the patients had varying heart-block and $\vec{\omega}$ occasionally sinus rhythm. Interference dissociation was frequently observed. The pacing impulse $\vec{x}$ must often have fallen within the 'vulnerablen period'. In spite of this no detectable ventricular $\rightarrow$ fibrillation ensued. Similarly, the animals havej paced satisfactorily. The threshold measurementso of the human patients have behaved in the predicted manner and clearly have been uninfluencede by this form of pacing. This experience supports the claim of Zoll, Frank, Zarsky, Linenthal, andฏ Belgard (1961) that threshold change is due entirely to the injurious effect of the foreigne electrodes and is in no way dependent on the nature of the electrical stimulus. A strong caseo could therefore be made out for adopting? 6 msec. pacing stimuli provided that still longer observation confirms that the patients continue too run no greater risk of ventricular fibrillation.

\section{CONCLUSIONS}

Threshold variation has been measured for? various pulse durations for up to 12 months.

The three main factors which influence the behaviour of the pacemaker-energy, currento drain, and threshold stability - have been assessed $x$ for different pulse durations.

We believe that a 6 -msec. duration impulse for cardiac pacemaking offers a significant improve-o극 ment in pacemaker design. Stability is enhanced to a high degree without the life being shortened 은

The $50 \%$ safety margin suggested for longer durations is more generous than that allowed in shorter pulse duration units.

Three patients have now been paced continuously with 6-msec. impulse pacemakers with- 오 out the development of ventricular fibrillation.w Serial measurements have confirmed that theire hearts now pace at lower voltages and currento than if 3-msec. impulses had been used.

The work of the Cardiovascular Research Unit is supported by grants from the C.S.I.R. (S.A.), the Wellcome Foundation, and the Johannesburg City Council. We wish to thank these organizations for their continued support. We should also like to thank Professor G. R. Bozzoli for reading this paper an for offering valuable suggestions. 


\section{REFERENCES}

Albert, H. M., Glass, B. A., Pittman, B., and Robichaux, P. (1964). Cardiac stimulation threshold: chronic study. Ann. N.Y. Acad. Sci., 111, 889.

Bruckman, S. K., Webb, R. C., Jr., and Bahnson, H. T. (1958). Monopolar ventricular stimulation for the control of acute surgically produced heart block. Surgery, 44, 910 .

Chardack, W. M., Gage, A. A., and Greatbatch, W. (1960). A transistorized self-contained, implantable pacemaker for the long-term correction of complete heart block. Ibid., 48, 643.

_ - (1961). Correction of complete heart block by a selfcontained and subcutaneously implanted pacemaker. Clinical experience with 15 patients. J. thorac. cardiovasc. Surg., 42, 814.

Furman, S., and Robinson, G. (1959). The use of an intracardiac pacemaker in the correction of total heart block. Surg. Forum, $1958,9,245$.

Kantrowitz, A. (1964). Implantable cardiac pacemakers. Ann. N.Y. Acad. Sci., 111, 1049.

Marchand, P., Jaros, G. G., and Obel, I. W. P. (1967). Problems with cardiac pacemakers. $S$. Afr. med. J., in press.

Nightingale, A... and Weale, F. E. (1960). Electrical stimulation of the dog's ventricle during atrioventricular block. Guy's Hosp. Rep., $109,147$.
Orias, O., Brooks, C. McC., Suckling, E. E., Gilbert, J. L., and Siebens, A. A. (1950). Excitability of the mammalian ventricle throughout the cardiac cycle. Amer. J. Physiol., 163, 272.

Prevost, J. L., and Battelli, F. (1899). Sur quelques effets des décharges électriques sur le cœur des mammifères. C.R. Acad. Sci. (Paris), 129, 1267.

Starzl, T. E., and Gaertner, R. A. (1955). Chronic heart block in dogs. A method for producing experimental heart failure. Circulation, 12, 259.

Weale, F. E.. Deuchar, D. C., and Nightingale, A. (1960). Electrical excitability of the human ventricular myocardium. Guy's Hosp. Rep., $109,157$.

Zoll, P. M. (1952). Resuscitation of the heart in ventricular standstill by external electric stimulation. New Engl. J. Med., 247, 768.

- Frank, H. A., Zarsky, L. R. N., Linenthal, A. J., and Belgard, A. H. (1961). Long-term electric stimulation of the heart for Stokes-Adams disease. Ann. Surg., 154, 330.

- and Linenthal, A. J. (1963). External and internal electric cardiac pacemakers. Circulation, 28, 455.

- Paul, M. H., Linenthal, A. J., Norman, L. R., and Gibson, W. (1956). The effects of external electric currents on the heart. Control of cardiac rhythm and induction and termination of cardiac arrhythmias. Ibid., 14, 745. 